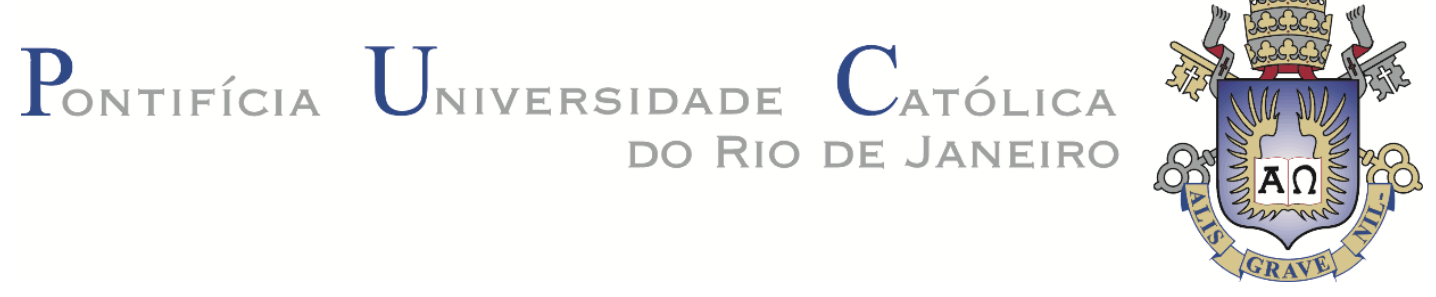

José Adriano Cardoso Malko

\title{
Aplicabilidade de Enzimas para Melhoramento de Solos em Pavimentação
}

Dissertação de Mestrado

Dissertação apresentada como requisito parcial para obtenção do grau de Mestre pelo Programa de Pós-Graduação em Engenharia Civil do Departamento de Engenharia Civil da PUC-Rio.

Orientadora: Profa ${ }^{a}$. Michéle Dal Toé Casagrande Co-orientador: Prof. Ben-Hur de Albuquerque e Silva 


\title{
Pontifícia $U_{\text {niversidade }}$ C atólica \\ DO RIO DE JANEIRO
}

José Adriano Cardoso Malko

\section{Aplicabilidade de Enzimas para Melhoramento de Solos em Pavimentação}

Dissertação apresentada como requisito parcial para obtenção do grau de Mestre pelo Programa de Pós-Graduação em Engenharia Civil do Departamento de Engenharia Civil do Centro Técnico Científico da PUC-Rio. Aprovada pela Comissão Examinadora abaixo assinada.

\author{
Profㄹ. Michéle Dal Toé Casagrande \\ Orientadora \\ Departamento de Engenharia Civil - PUC-Rio
}

Prof. Eurípedes do Amaral Vargas Júnior Departamento de Engenharia Civil - PUC-Rio

Prof. Antônio Carlos Rodrigues Guimarães

Instituto Militar de Engenharia

Prof. Rubens Brazetti

Universidade Tecnológica Federal do Paraná

Prof. José Eugenio Leal

Coordenador Setorial do Centro Técnico Cientifico - PUC-Rio

Rio de Janeiro, 04 de março de 2015 
Todos os direitos reservados. É proibida a reprodução total ou parcial do trabalho sem autorização do autor, da orientadora e da universidade.

\section{José Adriano Cardoso Malko}

Graduou-se em Engenharia Civil pela Univali (Universidade do Vale do Itajaí) em Itajaí, Santa Catarina em janeiro de 2013. Ingressou no mestrado na Pontifícia Universidade Católica do Rio de Janeiro em março de 2013, desenvolvendo dissertação na linha de pesquisa de Geotecnia Experimental aplicada a pavimentação.

Ficha Catalográfica

Malko, José Adriano Cardoso

Aplicabilidade de enzimas para melhoramento de solos em pavimentação / José Adriano Cardoso Malko; orientadora: Michéle Dal Toé Casagrande; co-orientador: Ben-Hur de Albuquerque e Silva. - Rio de Janeiro: PUC, Departamento de Engenharia Civil, 2015.

1.1. v., 121 f.: il. ; $29,7 \mathrm{~cm}$

Dissertação (mestrado) - Pontifícia Universidade Católica do Rio de Janeiro, Departamento de Engenharia Civil, 2015.

Inclui referências bibliográficas.

1. Engenharia Civil - Teses. 2. Melhoramento de solos. 3. Enzimas. 4. Pavimentação. 5. Ensaio LWT. I Casagrande, Michelé Dal Toé. II Silva, Ben-Hur de Albuquerque e. III Pontifícia Universidade Católica do Rio de Janeiro. Departamento de Engenharia Civil. IV Título.

CDD: 624 
Dedico esta dissertação ao meu pai José, a minha mãe Joise e a minha irmã Adrianí. Tudo o que sou devo a vocês. 


\section{Agradecimentos}

À vida, por todos os dias nos pregar peças, levando-nos pelos melhores caminhos, colocando-nos obstáculos a serem vencidos ao lado de pessoas incríveis, fazendo destes, momentos inesquecíveis.

À minha família, meu Pai José, minha Mãe Joise e minha Irmã Adrianí, sem vocês nada disso seria possível. Agradeço imensamente não somente essa, mas todas as oportunidades que me foram possíveis graças ao apoio que sempre tive de vocês. Sei que qualquer que sejam minhas escolhas, sempre terei vocês ao meu lado. Vocês são meu combustível e com certeza quero trazer cada vez mais orgulho pelos batalhadores que são. Muito obrigado por tudo, vocês são tudo para mim;

À Silviane, minha noiva, eterna companheira, que aceitou o desafio de morar no Rio de Janeiro, me acompanhar em um desafio que não imaginávamos como seria. Por todos os momentos de alegria, tristeza, estresse e brincadeiras, juntos crescemos ainda mais e ajudamos um ao outro nos piores momentos. Muito obrigado meu amor, por estar sempre ao meu lado me apoiando em todos os momentos que precisei, obrigado por estar sempre comigo, obrigado por tudo, todo e sempre;

À Professora, Orientadora e principalmente Amiga Michéle, que levarei comigo como exemplo de pessoa para o resto da vida. Desde o início quando cheguei na PUC me ajudou em todas as etapas do Mestrado, depositando uma imensa confiança em mim. Me fez ver que por mais difícil que as coisas possam parecer, sempre haverá uma forma de sair feliz e vitorioso. Me trouxe ao chão diversas vezes nos meus momentos avoados, soube lidar com minha personalidade, angústias e principalmente me aconselhou a respeito dos meus problemas. Não há palavras para lhe agradecer, só espero um dia poder retribuir tudo que fez e tem feito por mim. Muito obrigado do fundo do meu coração Mami;

Aos meus amigos, ou melhor, irmãos que ganhei no Rio de Janeiro, Nathalia e Fernando. Como já havia dito, sem vocês não seria possível. Obrigado todos os momentos inesquecíveis que passamos juntos, nos conhecemos a tão pouco tempo, porém, parece que somos amigos de infância. Sei que pude contar com vocês para 
os piores momentos que passei e tenho certeza que estarão disponíveis se eu precisar de alguma coisa. A recíproca é verdadeira. Obrigado de verdade manos;

Ao Professor Ben-Hur, por permitir que parte da pesquisa pudesse ser desenvolvida no Laboratório de Solos do Instituto Militar de Engenharia;

Ao Rubens Brazetti, por toda experiência a mim repassada sobre o tema pesquisado, aos momentos de descontração e risadas que me proporcionou e por toda ajuda;

Aos representantes dos produtos enzimáticos que forneceram amostras das enzimas utilizadas na pesquisa: TerraZyme - Nature Plus Inc, PermaZyme - Pacific Enzymes e EMC - Soil Stabilization Company;

Ao Bazan e a Nathalia Passos, que muito me auxiliaram quando cheguei no Rio, me dando toda a força e apoio necessário, obrigado por tudo e principalmente pelos momentos de confraternização;

Aos meus brothers Engenheiros, Alan, Cláudio, Fezão, Rosuel e Yuri. Por toda essa amizade, por todas as conversas e por todo o apoio que sempre recebi de vocês;

Ao Futsal do Mestres, pelo futsal de todo fim de semana no ginásio e pelas amizades cultivadas nos momentos de descontração ao longo de todo o período do Mestrado;

À todos os amigos da PUC, que direta e indiretamente contribuíram para a realização deste estudo;

Ao Vanderlei, Sargento Melo e a Claudeny pela ajuda nos ensaios no Laboratório de Solos do IME e por todos os momentos de descontração;

Ao Joel do Laboratório de Microscopia Eletrônica, Varredura e Transmissão do IME pela disponibilidade em ajudar com os ensaios no MEV e análise das imagens;

Ao Ramon do Laboratório de Difração de Raios-X do IME pela ajuda com a execução dos ensaios DRX nas amostras e análises;

À Professora Maria Isabel do Departamento de Química da PUC-Rio, pela disponibilidade em realizar os ensaios químicos nas amostras;

À todos os professores do Departamento de Engenharia Civil da PUC-Rio por todo conhecimento adquirido;

Aos funcionários do Departamento de Engenharia Civil da PUC-Rio, principalmente à Rita, pela colaboração e paciência;

Ao IME-Instituto Militar de Engenharia, pela disponibilidade na utilização dos laboratórios que permitiram o desenvolver conciso desta pesquisa;

À CAPES - Coordenação de Aperfeiçoamento de Pessoal de Nível Superior, pela concessão da bolsa de fomento;

À PUC-Rio - Pontifícia Universidade Católica do Rio de Janeiro e ao Departamento de Engenharia Civil, pela bolsa de isenção e a oportunidade em poder cursar o Mestrado em uma das mais renomadas instituições do país na área;

À Deus, por tudo! 


\section{Resumo}

Malko, José Adriano Cardoso; Casagrande, Michéle Dal Toé; Silva, Ben-Hur de Albuquerque e. Aplicabilidade de Enzimas para Melhoramento de Solos em Pavimentação. Rio de Janeiro, 2015. 121 p. Dissertação de Mestrado. Departamento de Engenharia Civil, Pontifícia Universidade Católica do Rio de Janeiro.

Nos últimos anos no Brasil houve uma grande oferta de aditivos patenteados (enzimas) ao mercado rodoviário, como solução de estabilização de solos. Porém, muitas vezes são rejeitados pelo fato de não haver embasamento teórico para comprovar tais utilizações e também pelos próprios pesquisadores não vislumbrarem oportunidades de pesquisas. De qualquer forma, esses produtos estão sendo comercializados e, em muitos casos, municípios e estados desperdiçam recursos ao optar por uma solução ainda não muito estudada. Na presente pesquisa, estudou-se a utilização de enzimas com aplicação em diferentes solos buscando seu melhoramento. Para isso, foi utilizado um simulador de tráfego portátil (Load Wheel Test - LWT), utilizado para avaliar o efeito da compactação e as características de deformação de camadas de revestimentos asfálticos. Para tal, foi utilizado um conjunto de diversos acessórios para moldagem de corpos de prova no formato de 380x50x10mm, podendo ser facilmente adaptados ao equipamento. Foram investigadas variáveis com três diferentes tipos de solos lateriticos, três diferentes tipos de enzimas, solo no estado puro e tratado com três variações de dosagem na aplicação das enzimas e quatro tempos de cura dos corpos de prova. Esses corpos de prova foram moldados e ensaiados a fim de obter uma série de resultados experimentais, seguiu-se um rigoroso cuidado na produção para garantir a igualdade e, posteriormente, poder comparar resultados do solo tratado com enzimas com o solo sem qualquer tipo de tratamento. Concluiu-se que os solos melhorados com enzimas mostraram-se eficazes para aplicação em pavimentos, sendo seu comportamento diferenciado pelo tipo de solo, tipo de enzima e teor de aplicação das mesmas, em alguns resultados apresentando melhorias acima de $500 \%$ quando comparado ao solo no estado puro.

\section{Palavras-chave}

Melhoramento de solos; enzimas; pavimentação; ensaio LWT 


\section{Abstract}

Malko, José Adriano Cardoso; Casagrande, Michéle Dal Toé (Advisor); Silva, Ben-Hur de Albuquerque e (Co-advisor). Applicability of Enzymes for Soils Improvement in Pavements. Rio de Janeiro, 2015. 121 p. Msc. Dissertation. Departamento de Engenharia Civil, Pontifícia Universidade Católica do Rio de Janeiro.

Recently in Brazil, there was a great offer of patented additives (enzymes) to the highway works as solution to soil stabilization. However, they are sometimes rejected because there are not enough theoretical knowledge to prove such use, and because researchers do not see it as a promising research field. Anyway, these products have been traded, and frequently, the counties and states waste their resources by choosing a solution that is not well studied yet. In the present research, it was studied the use of additives applied in some soils, aiming its stabilization. For this study, it was used a portable traffic simulator (Load Wheel Test - LWT), used to evaluate the effect of the compression and deformation characteristics of asphalt layers coatings. For that, it was used a set of several accessories for molding the specimens in 380x50x10mm format and can be easily adapted to the equipment. Were investigated three different types of lateritic soils, three different types of enzymes, soil in the pure state and treated with three dosage variations in the application of enzymes and four curing times of the specimens. These specimens were molded and tested in order to obtain a series of experimental results was followed a rigorous care in production to ensure equal and, subsequently, be able to compare the results of the soil treated with enzyme and the soil without any treatment. It was concluded that the soils improved with enzyme were effective for application in pavements, with their behavior distinguished by the type of soil, type of enzyme content and it application, in some results showing improvements over $500 \%$ compared to the soil in the pure state.

\section{Keywords}

Soils improvement; enzymes; pavements; Load Wheel Test (LWT) 


\section{Sumário}

1 Introdução 19

1.1 Relevância e Justificativa da Pesquisa 19

1.2 Objetivos 21

1.3 Estrutura da Dissertação 22

2 Revisão Bibliográfica 23

2.1 Considerações Iniciais 23

2.2 Estabilização de Solos 23

2.2.1 Estabilização Mecânica 25

2.2.2 Estabilização Física 25

2.2.3 Estabilização Química 26

2.3 Aditivos Orgânicos 35

2.3.1 Histórico 35

2.3.2 Enzimas Patenteadas 37

2.3.3 Pesquisas Realizadas 39

2.4 Considerações sobre a Revisão Bibliográfica 40

3 Programa Experimental 41

3.1 Considerações Iniciais $\quad 41$

3.2 Materiais Utilizados $\quad 41$

3.2.1 Solos 42

3.2.2 Enzimas 45

3.2.3 Água 45

$\begin{array}{lll}3.2 .4 & \text { Misturas } & 46\end{array}$

3.3 Ensaios Realizados 48

3.3.1 Coleta e Preparação das Amostras 48

3.3.2 Ensaios Físicos 49

3.3.3 Ensaios Químicos 56 
3.3.4 Ensaios Mecânicos 57

3.3.5 Micromorfologia e Mineralogia 80

4 Resultados e Discussões $\quad \mathbf{8 1}$

4.1 Considerações Iniciais $\quad 81$

4.2 Ensaios Físicos $\quad 81$

4.2.1 Análise Granulométrica 81

4.2.2 Massa Especifica Real dos Grãos 82

4.2.3 Limites de Atterberg 82

4.2.4 Classificação dos Solos 83

4.3 Ensaios Químicos 84

4.3.1 Composição Química 84

4.3.2 Teor de Matéria Orgânica 88

4.4 Ensaios Mecânicos 88

4.4.1 Ensaio de Compactação 88

4.4.2 Ensaio de Índice de Suporte Califórnia 89

4.4.3 Ensaio LWT - Load Wheel Test 90

4.4.4 Compressão Simples 100

4.5 Micromorfologia e Mineralogia 102

4.5.1 Micromorfologia - Microscopia Eletrônica de Varredura 102

4.5.2 Mineralogia - Difração de Raios-X 106

5 Conclusões e Sugestões para Futuros Trabalhos 111

5.1 Conclusões 111

5.2 Sugestões para Futuros Trabalhos 113

6 Referências Bibliográficas 114

$\begin{array}{ll}\text { Anexo I } & 120\end{array}$

Carta de Reconhecimento de Baixa Intensidade dos Solos do Estado do Rio de Janeiro 


\section{Lista de Figuras}

Figura 2-1 - llustração da reação gerada com a adição de enzima ao solo (EMC, 2014)

Figura 3-1 - Localização da jazida onde foram retirados os solos do presente estudo

Figura 3-2 - Detalhe da jazida onde foram retirados os solos do presente estudo

Figura 3-3 - Perfil com os três diferentes solos desta pesquisa 43

Figura 3-4 - Solos utilizados no presente estudo 43

Figura 3-5 - Solo preto utilizado no presente estudo 44

Figura 3-6 - Solo amarelo utilizado no presente estudo 44

Figura 3-7 - Solo vermelho utilizado no presente estudo 45

Figura 3-8 - Enzimas em solução de 3\% (em volume) em água utilizadas no presente estudo

Figura 3-9 - Perda de massa por imersão do solo vermelho do presente estudo

Figura 3-10 - Equipamento LWT - detalhes.

Figura 3-11 - Materiais e ferramentas utilizados no preparo da amostra para o corpo de prova - etapa 1

Figura 3-12 - Preparo da amostra de solo para corpos de prova 63

Figura 3-13 - Preparo da solução com a enzima 64

Figura 3-14 - Mistura do solo com água-enzima 65

Figura 3-15 - Equipamento e ferramentas utilizados no preparo da amostra - etapa 2 - parte 1

Figura 3-16- Preparação do molde para preparação do corpo de prova

Figura 3-17 - Preparação do molde para preparação do corpo de prova (continuação)

Figura 3-18 - Preparação do corpo de prova - compactação manual 
Figura 3-19 - Ferramentas e equipamento utilizados no preparo da amostra - etapa 2-parte 2

Figura 3-20 - Compactação do corpo de prova na prensa

Figura 3-21 - Compactação do corpo de prova na prensa (continuação)

Figura 3-22 - Extração do corpo de prova do molde 73

Figura 3-23 - Extração do corpo de prova (continuação) 74

Figura 3-24 - Procedimento de cura dos corpos de prova 75

Figura 3-25 - Equipamento e ferramentas utilizadas durante a etapa de ruptura do corpo de prova $\quad 75$

Figura 3-26 - Montagem do LWT para ruptura do corpo de prova $\quad 76$

Figura 3-27 - Ruptura do corpo de prova 77

Figura 3-28 - Ruptura do corpo de prova (continuação) 78

Figura 3-29 - Equipamento utilizado para ruptura dos corpos de prova a compressão simples no laboratório de solos do IME

Figura 4-1 - Resultados das análises granulométricas do presente estudo

Figura 4-2 - Classificação MCT para o solo preto estudado 83

Figura 4-3 - Classificação MCT para o solo amarelo estudado 84

Figura 4-4 - Classificação MCT para o solo vermelho estudado $\quad 84$

Figura 4-5 - Composição dos elementos químicos do solo preto do presente estudo

Figura 4-6 - Composição dos elementos químicos do solo amarelo do presente estudo

Figura 4-7 - Composição dos elementos químicos do solo vermelho do presente estudo

Figura 4-8 - Composição dos óxidos do solo preto do presente estudo 86

Figura 4-9 - Composição dos óxidos do solo amarelo do presente estudo

Figura 4-10 - Composição dos óxidos do solo vermelho do presente estudo

Figura 4-11 - Curvas de compactação dos solos deste estudo

Figura 4-12 - Representação gráfica dos resultados de ISC dos solos estudados

Figura 4-13 - Resultados ensaio LWT utilizando enzima EMC 
Figura 4-14 - Resultados ensaio LWT utilizando enzima TZ 93

Figura 4-15 - Resultados ensaio LWT utilizando enzima PZ 94

Figura 4-16 - Resultados ensaio LWT utilizando dosagem 1:40 96

Figura 4-17 - Resultados ensaio LWT utilizando dosagem 1:30 97

Figura 4-18 - Resultados ensaio LWT utilizando dosagem 1:20 99

Figura 4-19 - Variação do tempo de cura (solo preto, enzima PZ, dosagem 1:20) 100

Figura 4-20 - Corpo de prova para ensaio de compressão simples solo preto puro 101

Figura 4-21 - Compressão simples - solo preto puro e tratado com PZ 101

Figura 4-22 - Microscopia eletrônica de varredura - solo vermelho puro e tratado com PZ 1:20 (100x, 200x e 2000x)

Figura 4-23 - Microscopia eletrônica de varredura - solo amarelo puro e tratado com PZ 1:20 (100x, 200x e 2000x) 104

Figura 4-24 - Microscopia eletrônica de varredura - solo preto puro e tratado com PZ 1:20 (100x, 200x e 2000x)

Figura 4-25 - Microscopia eletrônica de varredura - solo preto puro e tratado com PZ 1:20 (50.000 e 100.000x)

Figura 4-26 - Resultado de difração de raios-x do solo preto no estado puro

Figura 4-27 - Resultado de difração de raios-x do solo preto tratado com enzima PZ

Figura 4-28 - Resultado de difração de raios-x do solo amarelo no estado puro

Figura 4-29 - Resultado de difração de raios-x do solo amarelo tratado com enzima $\mathrm{PZ}$

Figura 4-30 - Resultado de difração de raios-x do solo vermelho no estado puro

Figura 4-31 - Resultado de difração de raios-x do solo vermelho tratado com enzima $\mathrm{PZ}$ 


\section{Lista de Tabelas}

Tabela 3-1 - Misturas solo-enzimas estudadas

Tabela 3-2 - Valores tipicos de c' para diferentes granulometrias de solos (Nogami e Villibor, 1995)

Tabela 3-3 - Valores tipicos de d' para diferentes granulometrias de solos (Nogami e Villibor, 1995)

Tabela 3-4 - Equipamento e ferramentas utilizados no preparo da amostra - etapa 2-parte 1

Tabela 3-5 - Cargas sobre o corpo de prova a cada 1000 passadas 77

Tabela 4-1 - Resultados das análises granulométricas do presente

Tabela 4-2 - Resultados dos ensaios de densidade real dos grãos do presente estudo

Tabela 4-3 - Resultados dos ensaios de limites de Atterberg do presente estudo

Tabela 4-4 - Teor de matéria orgânica dos solos do presente estudo 88

Tabela 4-5 - Resultados dos ensaios de compactação 88

Tabela 4-6 - Resultados de ISC para os solos estudados 89

Tabela 4-7 - Resultados de expansão aos 4 dias de imersão 89 


\section{Lista de Abreviaturas}

\begin{tabular}{|c|c|c|}
\hline & ABNT & Associação Brasileira de Normas Técnicas \\
\hline & ABPv & Associação Brasileira de Pavimentação \\
\hline & BT & Bloco de Teste \\
\hline & CBR & California Bearing Ratio \\
\hline & $\mathrm{CP}$ & Corpo de Prova \\
\hline & DNER & Departamento Nacional de Estradas de Rodagem \\
\hline & DNIT & Departamento Nacional de Infraestrutura de Transportes \\
\hline & EMBRAPA & Empresa Brasileira de Pesquisas Agropecuárias \\
\hline & EMC & Enzima Earth Materials Catalyst \\
\hline & $\mathrm{PZ}$ & Enzima PermaZyme \\
\hline & $\mathrm{TZ}$ & Enzima TerraZyme \\
\hline & FHWA & Federal Highway Administration - USA \\
\hline ָू & HRB & Highway Research Board \\
\hline$\frac{N}{m}$ & COPPE & Instituto Alberto Luiz Coimbra de Pós-Graduação e Pesquisa \\
\hline$\stackrel{0}{2}$ & IPR & Instituto de Pesquisas Rodoviárias \\
\hline 颉 & IME & Instituto Militar de Engenharia \\
\hline 范 & LVA & Latossolo Vermelho-Amarelo Distrófico \\
\hline 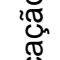 & LWT & Load Wheel Test \\
\hline & MEAS & Massa Especifica Aparente Seca \\
\hline ऽั & MCT & Miniatura Compactada Tropical \\
\hline$\stackrel{1}{\simeq}$ & NBR & Norma Brasileira \\
\hline 苮 & PUC-Rio & Pontifícia Universidade Católica do Rio de Janeiro \\
\hline & EDX & Raios-X por Energia Dispersiva \\
\hline & RSU & Resíduos Sólidos Urbanos \\
\hline & $\mathrm{SE} / 2$ & Seção de Ensino de Engenharia de Fortificação e Construção \\
\hline & SUCS & Sistema Unificado de Classificação dos Solos \\
\hline & USA & United States of America \\
\hline & UFRJ & Universidade Federal do Rio de Janeiro \\
\hline
\end{tabular}




\section{Lista de Símbolos}

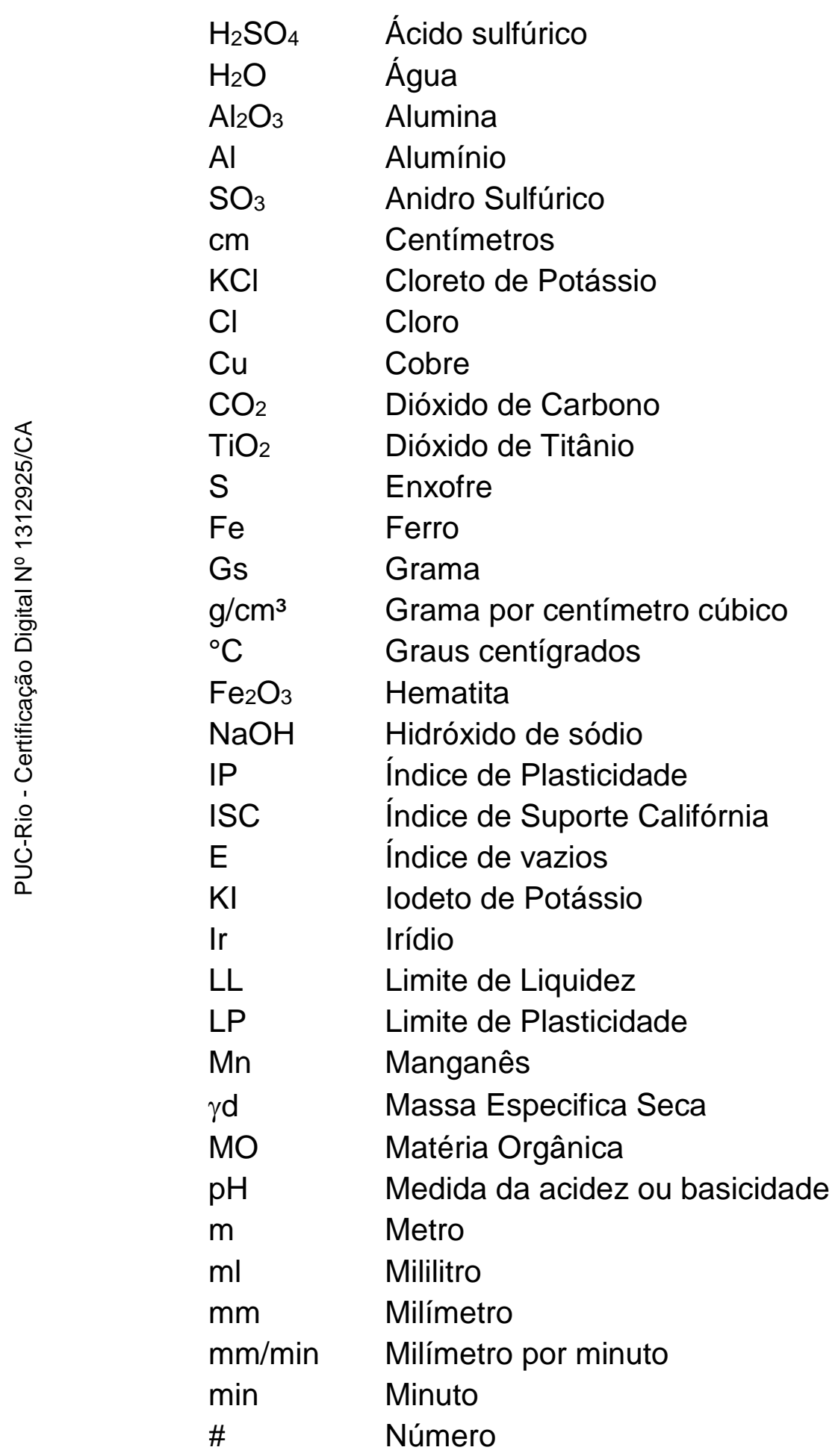




\begin{tabular}{|c|c|c|}
\hline & $\mathrm{CaO}$ & Óxido de Cálcio \\
\hline & $\mathrm{PbO}$ & Óxido de Chumbo (II) \\
\hline & $\mathrm{CuO}$ & Óxido de Cobre (II) \\
\hline & $\mathrm{Cr}_{2} \mathrm{O}_{3}$ & Óxido de Crômio (III) \\
\hline & $\mathrm{SrO}$ & Óxido de Estrôncio \\
\hline & $\mathrm{MgO}$ & Óxido de Magnésio \\
\hline & $\mathrm{MnO}$ & Óxido de Manganês (II) \\
\hline & $\mathrm{K}_{2} \mathrm{O}$ & Óxido de Potássio \\
\hline & $\mathrm{Na}_{2} \mathrm{O}$ & Óxido de Sódio \\
\hline & $\mathrm{ZnO}$ & Óxido de Zinco \\
\hline & $\mathrm{ZrO}_{2}$ & Óxido de Zircônio \\
\hline & $\mathrm{P}_{2} \mathrm{O}_{5}$ & Pentóxido de Fósforo \\
\hline & $\mathrm{V}_{2} \mathrm{O}_{5}$ & Pentóxido de Vanádio \\
\hline & Gs & Peso específico \\
\hline & $"$ & Polegadas \\
\hline & pol & Polegadas \\
\hline & $\%$ & Porcentagem \\
\hline & K & Potássio \\
\hline & kN & Quilo Newton \\
\hline & $\mathrm{kPa}$ & Quilo Pascal \\
\hline & $\mathrm{kg}$ & Quilograma \\
\hline & $\mathrm{kgf} / \mathrm{m}^{2}$ & Quilograma força por metro quadrado \\
\hline & $\mathrm{kg} / \mathrm{m}^{3}$ & Quilograma por metro cúbico \\
\hline & $\mathrm{SiO}_{2}$ & Sílica \\
\hline & $\mathrm{Si}$ & Silício \\
\hline & $\mathrm{Ti}$ & Titânio \\
\hline & t & Tonelada \\
\hline$\subseteq$ & t/ano & Tonelada por ano \\
\hline & w & Umidade \\
\hline & $\mathrm{V}$ & Vanádio \\
\hline & $\mathrm{Zn}$ & Zinco \\
\hline & $\mathrm{Zr}$ & Zircônio \\
\hline
\end{tabular}


How pale and tedious this world would be without mystery

Ibn Sina

The important thing is not to stop questioning. Curiosity has its own reason for existing

Albert Einstein

However bad life may seem, there is always something you can do, and succeed at. While there's life, there is hope

Stephen Hawking 